\title{
Mastering the scientific peer review process: tips for young authors from a young senior editor
}

\author{
Evgenios Agathokleous ${ }^{1}$
}

Received: 14 July 2021 / Accepted: 20 August 2021 / Published online: 16 September 2021

(C) Northeast Forestry University 2021

\begin{abstract}
Are you a student at a higher institution or an early-career researcher who is striving to understand and master the peer review process so to increase the odds of getting a paper published in the Journal of Forestry Research or another reputable, peer-reviewed, scientific journal? In this paper, a young, senior editor provides a handbook of the peer review process based on his decadal experience in scientific publishing. He covers major information you need to know during the entire process, from selecting journals to completing the proofing of your accepted paper. He introduces key points for consideration, such as avoidance of predatory journals, dubious research practices and ethics, interaction with peers, reviewers, and editors, and the pursuit of aretê. Finally, he points out some common statistical errors and misconceptions, such as $\mathrm{P}$ hacking and incorrect effect size inference. He hopes that this paper will enhance your understanding and knowledge of the peer-review process.
\end{abstract}

Keywords Academic editor - Article publishing . Manuscript status $\cdot$ Science communication $\cdot$ Scientific writing

Project Funding: The author acknowledges support by the Startup Foundation for Introducing Talent of Nanjing University of Information Science \&Technology (NUIST), Nanjing, China (Grant No. 003080).

The online version is available at http://www.springerlink.com

Corresponding editor: Yu Lei.

Evgenios Agathokleous

evgenios@nuist.edu.cn

1 Department of Ecology, School of Applied Meteorology, Nanjing University of Information Science and Technology (NUIST), Nanjing 210044, People's Republic of China

\section{Introduction}

We live in a world where scientific publishing and thus peer review have become a major determinant of career development and success or failure (Neill 2008; Fanelli 2010; Van Wesel 2016; Fanelli and Larivière 2016; Vuong 2019). Improvement of humans' daily lives and advancement of societies also depend upon the production of scientific knowledge and dissemination of research results (Böhme and Stehr 1986; Stehr 2009; de Camargo Jr 2011; Thorlindsson and Vilhjalmsson 2016), which often are the only means by which humanity can manage and overcome global crises, such as the current COVID-19 pandemic due to the severe acute respiratory syndrome coronavirus 2 (SARS-CoV-2) (Hu et al. 2020; COVID-19 Host Genetics Initiative 2021; Perreau et al. 2021; Solís et al. 2021; Telenti et al. 2021).

The Journal of Forestry Research (JFR) was founded in 1990 and published under the title 'Journal of Northeast Forestry University' (English Edition) during the first seven years. During that period JFR was an institutional journal with almost all its published papers coming from Northeast Forestry University, China. In 1997, the journal adopted its current title, and, in 2002, it was jointly sponsored by the Northeast Forestry University and the Ecological Society of China. During the period 1997-2002, JFR had expanded to cover the entire nation, and most submissions came from institutions across China. JFR noted a major turn in 2007 when it collaborated with Springer Verlag to deliver its content to an international readership. This contributed to achieving about $85 \%$ of the total papers published in the journal coming from international researchers. Beginning from the first issue of Volume 24, in 2013, JFR is included in the Thomson Reuters' Science Citation Expanded (SCIE) and Journal Citation Reports (JCR)/Science Edition. With an authorship covering over sixty countries, JFR is operated 
by a team of 55 affiliated academic editors from eighteen countries, five in-house publication editors, and four language editors.

Based on the latest Clarivate Analytics' JCR published on 30 June, 2021, the 2020 Impact Factor (IF) of JFR has increased to 2.149, ranking 24th among 67 journals of Forestry (Q2), marking a new point in the history of its publication by exceeding an IF of 2.0. The new IF noted an important increase compared to the 2019, 2018, and 2017 IFs of $1.689,1.155$, and $0.748(\mathrm{Q} 3)$, respectively. The IF should not be the only criterion of the quality of journals (Covaci et al. 2019) and does not serve as an index of the quality of individual articles. That is, the IF value is highly affected by the skewness in the data distribution introduced by only a small fraction of highly-cited papers in a journal (Lozano et al. 2012; Larivière et al. 2016). Some journals have discontinued its use and some countries have recently restricted the use of the SCI system in academic evaluations (Verma 2015; Fernandez-Llimos 2016; Qian et al. 2020; Zhu 2020). The trend of JFR's metrics over the recent years, however, suggests an upward trajectory of the journal's impact and visibility.

As JFR is transforming into a more competitive international journal, one that is less affected by profit agendas, ${ }^{1}$ a more active engagement of young audience, i.e. early-career researchers and students, can be expected. Global health emergencies, however, can impact research laboratories, indicating a need for developing diverse skills to enhance lab health and resilience (Maestre 2019; Rillig et al. 2020). The recent pandemic, by urging for shutting down scientific research labs around the globe, might affect the training of many young authors, whose physical interaction with supervisors and mentors might be impeded. These prompted the synthesis of a paper that can serve as a handbook for publishing scientific papers and engaging in the peer reviewer process, especially during the current pandemic, which may be a good time for young researchers to start writing. This is a personal reflection based on my approximately decadal experience in scientific publishing, as a young ${ }^{2}$ Associate Editor-in-Chief of JFR and editor at different ranks in several other journals, ${ }^{3}$ a reviewer of approximately 550 articles for about 80 international peer-reviewed journals, and author of some $135 \mathrm{SCI}$ articles, of which 65 as first author and the vast majority published in Q1 and Q2 journals. ${ }^{4}$ I hope that this piece will transfer to you knowledge that would otherwise need physical interaction with your teachers,

\footnotetext{
${ }^{1}$ JFR is directed and published by the Northeast Forestry University, China, in collaboration with a publisher (currently Springer).

2 Born in January, 1988.

${ }^{3}$ Forestry Research, Science of The Total Environment, Current Opinion in Environmental Science \& Health, Plant Stress, Climate, Sci, Frontiers in Forests and Global Change, and Water Emerging Contaminants \& Nanoplastics.
}

supervisors, or mentors, thus facilitating the development of your skills. Abraham Lincoln, the U.S. 16th president and the man who led through the American Civil War, once said "give me six hours to chop down a tree and I will spend the first four sharpening the axe", meaning that we should devote resources to master the tools needed to achieve our goals.

\section{Before starting the drafting process}

\section{Select your target journal}

Have you completed your manuscript and are now searching for candidate journals (Hites 2021)? Yellow card. While this is an often observed practice, I believe it's less appropriate. Based on my experience, I find it more efficient in terms of time and effort to target a journal much before starting to synthesize your paper (Fig. 1). Why is that? The Introduction $^{5}$ highly depends on the journal; so does the discussion (e.g. of the results if it's an original research article) and even the abstract and conclusions. For example, the first paragraph opening the paper might relate to the aims and scope of the journal, e.g. indicating the environmental issue if it's an environmental journal or the forestry relevance if it's a forestry journal. Likewise, the last paragraph of Introduction might expose the significance of the study for the broader readership of the journal. The focus of certain aspects of the study in the paragraphs in between the first and last of the Introduction should also be with respect to the journal aims and scope. Hence, zeroing in on a specific journal a priori and fitting the Introduction to the aims and scope of the journal can save you time and effort from editing your Introduction later on to match the journal's scope. A friendly, but believingly important, suggestion is to avoid sending pre-submission inquiries to the journal editors, unless it's stated otherwise in the author guidelines for some specific article types, because they may be problematic, counterproductive, and unnecessary (Levesque 2019). Selecting your

\footnotetext{
${ }^{4}$ Note: This does not imply that the longer someone is engaging in a process the more skilled he/she is. The skills do not necessarily improve with increasing time span of engagement, but they do improve with increasing time of actual effort put into producing, reviewing, or editing papers. Also, the number of papers alone does not necessarily say much about one's authoring skills, whereas indices of papers' and journals' quality may be more appropriate.

5 Commonly the first section of any paper, which introduces the background and research questions/hypotheses, and sets the scene, although for some journals it can be named differently depending on the article type.
} 
Fig. 1 Tips to consider prior to drafting the paper

\section{Before starting the drafting process}

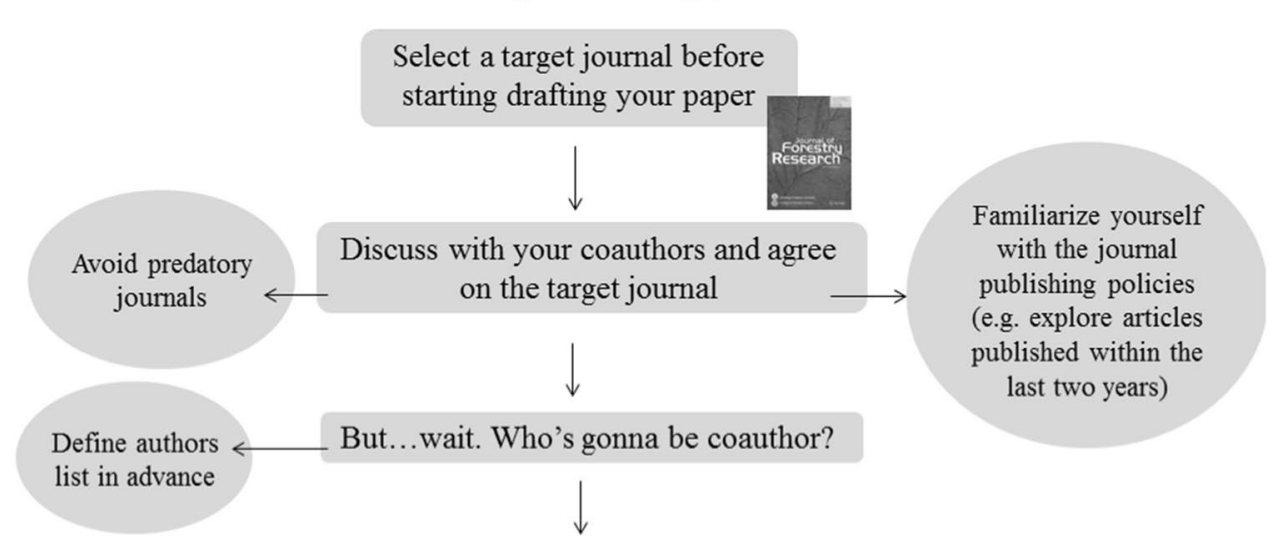

Be aware of dubious research practices target journal in advance can also facilitate collaborations, especially for article types other than original research articles (e.g. literature review articles (Sayer 2018)) where different people may be assigned to synthesize a specific section/topic of the article. By selecting the target journal a priori, you can comply with the journal's guidelines from the beginning by setting size limits specific to each section. This can finally save time to your colleagues by often avoiding unnecessary reductions of text later on; time is precious and perhaps nobody wants to spend time unnecessarily. I've seen cases where the lead authors of such collaborative review articles don't consider these from the beginning, letting independently-working people synthesize their sections without any specific guidelines as to the size. This policy finally leads to an excessively long manuscript that most journals (at least lead journals) would barely consider. But this can be an embarrassing outcome to some collaborators as more and more edits may be needed (more time), and finally having the paper published in a low-profile journal. I don't think this is what one wants. Considering all these from the early stages shows professionalism, and your colleagues will appreciate this. It may help you sustain longterm collaborations.

When selecting journal, if you've already prepared your degree's thesis, pay a visit to your reference list. The most cited journal is perhaps where you would submit your article. If you haven't worked on your thesis, your supervisor can direct you because senior researchers often select journals based on their experiences in a broader context, including previous experiences with interacting with journals as authors, reviewers, and editors.

Have a look at the indices of publication speed of the journal. You can usually find these on the journal's website. However, remember that the numbers you see are usually average numbers reflected by the arithmetic mean of the articles published by the specific journal within a specific time window. Arithmetic means are sensitive to data distribution skewness, i.e. asymmetry around the mean resulting in leftor right-tailed skewness, and the metrics you see reflect only an average performance, which doesn't make much sense in the absence of some measure of dispersion such as standard deviation. If we consider the articles published in a specific time window a sample of observations, the phenomenon of skewness may be more pronounced in journals publishing a relatively small number of papers in a year. The central limit theorem (CLT) states that as the sample size increases, the sampling distribution of the arithmetic mean approaches a Gaussian distribution (bell-shaped). This suggests that the relevant metrics of journals publishing a relatively high number of papers in a specific time window would be less prone to skewness. Hence, now you understand that some papers published even in journals offering rapid peer review can exhibit a considerably delayed peer review, i.e. these cases occur a few standard deviations from the mean.

If you cannot find any metrics of publication speed, you can sample several recent papers from the archives of the journal and see when the paper was submitted and when it was finally accepted for publication. By doing so, you'll have an image of how speedy the peer review might be, if you're concerned with the time needed for peer review. If you're a more experienced author who publishes many papers per year, you shall expect that the review duration may be considerably prolonged for some of your papers. Hypothesizing that an author submits approximately 30 papers in a year (a moderate sample size on a normal distribution basis), the duration of the review process is likely to follow a Gaussian distribution with some papers being reviewed within a relatively very short time (left tail) and some within a far longer time (right tail). The entire process is characterized by high relativity and is driven by probabilities. Therefore, the earlier you accept these, the earlier you may free yourself from potentially high anxiety. 
As a final tip, when you're searching for the right journal and have the information fresh, write down at least 2-3 more journals, perhaps ranked by preference, because you may need them. Selecting a thematic group of journals might also come in handy. For example, assuming that a paper reports novel findings about real-world interactive effects of microplastics and antibiotics on biota, it could be published into various journals, such as Journal of Hazardous Materials, Science of the Total Environment, Chemosphere, Environmental Pollution, and Environmental Sciences Europe. Nowadays there is considerable overlap between journals, and this can be seen as an opportunity to select a thematic group of journals for potentially successive submissions.

\section{Avoid predatory journals}

In the process to select journal, be careful to avoid predatory journals (Clark and Thompson 2017; Pourret et al. 2020; Qehaja 2020; Sonne et al. 2020; Macháček and Srholec 2021). Predatory means "inclined or intended to injure or exploit others for personal gain or profit" (Merriam-Webster Inc.), and authorship of a paper published in a predatory journal may harm your reputation and career (Clark and Thompson 2017). For an experienced author, it's easy to immediately realize that such an invitation to submit articles comes from a predatory journal or is a scam because reputable journals and publishers send standard formal invitations through their online submission systems (e.g. Editorial Manager for JFR), although there can often be an initial informal contact by an academic editor or a journal staff. Invitations to submit articles to a journal that are sent from non-institutional email addresses, e.g. gmail, hotmail, yahoo, outlook, and whatsnot, shouldn't be trusted; most publishers also discourage the use of non-institutional email addresses when it comes to the submission/peer-review system. In any case, if you're in doubt, you may seek advice from your supervisor or experienced colleagues.

\section{Familiarize yourself with the selected journal}

Let's assume you've selected a journal. Now what? If you're unfamiliar with the journal as author, reader, or reviewer, I suggest that you explore the archives of the journal, especially emphasizing on articles published within the last two years. Do you still believe your article would be a good fit to the articles collection of the journal? Will your article be of similar or higher quality than papers published on a similar subject? If there're other papers on the exact subject, does your paper provide sufficient scientific advance over the already published articles? If your answer to these questions is negative, then perhaps you should try to find another journal. Hence, as it's already clear to you now, this stage should be undertaken before selecting a target journal if you're unfamiliar with the journal or if you aren't regularly following the journal's publications as a reader. While you're exploring journal's articles, remember to pay attention to the quality of presentation, which is an important indicator of your article's quality (Sedlak 2015). Reaching a similar or higher quality of presentation, including the way display elements are designed, will likely increase your odds to get your paper published in your target journal. Above all, it shows some level of professionalism and proficiency-it's the small details that matter, right?

Once you've selected the journal, go through the author guidelines carefully. Do this right away. It's an important step that can help you utilize your time more effectively. For example, each journal has its own policy regarding article size/length, although some journals may haven't. This is important to note because you may find that you prefer another journal that allows articles to occupy more space. For example, Ecotoxicology and Environmental Safety states that "regular research articles must not exceed 8,000 words. Word limit here is for text only. In principle the number of tables and figures should not collectively exceed seven", while requiring the agreement of editors should the authors want to exceed their limits (author guidelines ${ }^{6}$; accessed on 13 July, 2021). On the other hand, Environmental Science \& Pollution Research states "please ensure that the length of your paper is in harmony with your research area and with the science presented", not imposing such limitations (author guidelines ${ }^{7}$; accessed on 13 July, 2021). Similarly, the editors of Environment International believe that "no single format can accommodate all useful contributions" and set no size limits to original research articles (author guidelines $^{8}$; accessed on 13 July, 2021). There're more such journals. Most journals, however, also allow online-only supplementary materials of any size nowadays, but it's important to know these in advance so to prepare your paper accordingly.

"Rules are useful, but the understanding of the reason on which a rule is based is better.”Thomas Arthur Rickard, author of a 1908' book (Rickard and Gayley 1908).

With this quote in mind, I suggest that you don't go mechanically through the author guidelines. Focus and try to understand them well. Ask yourself why a rule exists. Rules are important to maintain a journal's standards, and failing to comply with the author guidelines can lead to desk rejection of a paper (i.e. rejection by the editors at the initial screening), although for less important requirements, such as line spacing, margin widths, and bibliographic style, the

\footnotetext{
6 https://www.elsevier.com/journals/ecotoxicology-and-environmen tal-safety/0147-6513/guide-for-authors

7 https://www.springer.com/journal/11356/submission-guidelines

8 https://www.elsevier.com/journals/environment-international/01604120/guide-for-authors
} 
paper may be returned to you for further editing and reuploading (Lang 2020; Lowry et al. 2020). Here, I should also emphasize that it's not only authors that are responsible to comply with journals' guidelines. Journals are also responsible to provide clear and explicitly explained guidelines, yet there're often unclear guidelines (Lang 2020), explaining also the reasons of the 'rules'. For example, a beginner author may be confused by the guidelines of Environmental Research stating "tables should be separate from the manuscript text, and can be uploaded individually or consolidated into a single file" and "tables can be placed either next to the relevant text in the article, or on separate page(s)" (author guidelines, ${ }^{9}$ accessed on 13 July, 2021). Nevertheless, someone experienced with the journal would know that the editors would be fine with either choice. If you believe that some rules are unclear, you can contact the editorial office for clarifications; avoid contacting academic editors for technical issues.

\section{Be aware of dubious research practices}

Emerged from the need to reduce dubious research practices, new initiatives appear in several countries aiming at educating scientific researchers about responsible conduct of research, research misconduct, data handling, rules of collaborative research, conflicts of interest, and communicating information, amongst others. A good example of this is the founding of the Japan's Association for the Promotion of Research Integrity (APRIN) on 1 April, 2016, which provides important educational materials that are also used for the training of researchers at governmental institutions across the country (https://www.aprin.or.jp/en). Responsible conduct of scientific research encompasses (1) correct conduct of the research itself, (2) appropriate dealing with research subjects (e.g. humans and other animals), and (3) "accountability to society that supports research" (APRIN educational materials, update on 3 July, 2017). Research progress and scientific knowledge can significantly impact societies and drive/control the development of humanity (Iaccarino 2001). The society's trust to science also depends upon ethical conduct of research, and research misconduct can harm the mutualistic relationship between science and society. Hence, it's of utmost importance to have a good understanding of what can be harmful to science and society when preparing your paper. Ethical compass can also be critical in times of crises, as is the case of COVID-19 pandemic (Xafis et al. 2020; Maccaro et al. 2021).

There are various practices that are considered inappropriate in terms of research ethics, ${ }^{10}$ such as plagiarism, data

\footnotetext{
9 https://www.elsevier.com/journals/environmental-research/00139351/guide-for-authors
}

fabrication or falsification, salami slicing, duplicate publication, and ghost authors, which threaten scientific integrity (Rawat and Meena 2014). I recommend having these on your radar before starting to draft your paper to save otherwise lost time and protect your reputation and career, because the conduct of fraudulent research can lead to social, legal, and financial consequences (Resnik 2014; Eungoo and Hwang 2020). While I summarize major issues in this section, you may read more about these and other issues of integrity in scholarly research and its publication on the website of the Committee on Publication Ethics (COPE; https://publicatio nethics.org/) and the U.S. Office of Research Integrity (ORI; https://ori.hhs.gov/).

Plagiarism is the phenomenon where authors merely copy or slightly edit text from other manuscripts authored by other authors or them (so called self-plagiarism), often with not even citing the source. This phenomenon has been occurring for quite a long time (Duggan 2007), appears more frequently in papers authored by people whose native language is not English (Higgins et al. 2016), and is considered theft or misappropriation of intellectual property (Kumar et al. 2014). Plagiarism can result in rejection of your paper or retraction if revealed after its publication as well as to your suspension or ban from the journal (Das and Panjabi 2011), a situation you don't want to flirt with. Knowing and, thus, avoiding plagiarism during your writing is important (Gerding 2012; Kumar et al. 2014). Legitimate scientific journals evaluate your paper for plagiarism, similarity, and potential duplicate publication upon submission. Therefore, your paper will be desk rejected if found to be problematic. Don't think that your paper may be lucky not to be checked because many legitimate journals don't require an operator to do this. Instead, it's done automatically by the submission system, and editors can simply see the result attached next to your submission. I should also highlight that, on the other hand, being well aware can also protect you from potentially incorrect rejections. For example, a system that is widely used for similarity screening by numerous journals published by various publishers is iThenticate (Turnitin, LLC; https://www.ithenticate.com/). However, this software has important limitations such as no proper consideration of the Materials and Methods section, no sub-analysis of the various sections, and no exclusion of title pages, author's affiliations, funding and conflict of interest statements, and acknowledgements (Higgins et al. 2016). These can lead to an (incorrectly) high value of similarity, a single score that the software provides. Then, no careful detailed screening by an editor can lead to potentially incorrect rejection due to high similarity. Furthermore, this software doesn't provide a

\footnotetext{
${ }^{10}$ From the Greek word $\dot{\eta} \theta o \varsigma$ (ethos). As a concept, ethics was intro-
} duced by the Greek philosopher Aristotle (Iaccarino 2001). 
score of plagiarism but a score of similarity (e.g. the similarity index of this submission scored 3\%). While plagiarism accounts for similarity, similarity doesn't necessarily mean plagiarism. If your paper is rejected by an editor accusing you for plagiarism while you're sure your paper doesn't include plagiarism, alas, it's a serious issue because it indicates unethical practice from your side. In such a case, you may write a detailed letter to the journal office. For example, you may request that the journal examine the issue in detail and, if you're right, to rescind the editor's decision because the existence of such an incorrect accusation in the journal's record may harm your reputation and career in ways that you cannot imagine or expect.

Don't fabricate or falsify data/results. The ORI defines fabrication the phenomenon of "making up data or results and recording or reporting them" and falsification the phenomenon of "manipulating research materials, equipment, or processes, or changing or omitting data or results such that the research is not accurately represented in the research record" (https://ori.hhs.gov/definition-research-misconduct). In general, based on ORI's definitions, keep in mind not to (1) make up data or results and record or report them, (2) manipulate research materials, equipment, or processes, or (3) edit or omit data or results that lead to inaccurate representation. You may want to have a further reading about these issues (Resnik 2014; Kingori and Gerrets 2016; Eungoo and Hwang 2020), but you can always turn to your supervisor or other senior colleagues for advices if you have doubts whether a practice may consist data fabrication or falsification.

Don't perform salami or duplicate publishing. Salami slicing or 'least publishable unit' is the phenomenon where authors try to publish more than one papers, each of which including the least possible data/information of a specific research. Duplicate publication is the phenomenon where authors publish the same data/results in more than one papers, often by submitting them in different journals at around the same time or at different times. Both practices are inappropriate and can seriously harm one's career. Duplicate publishing is easier to define and identify, but salami slicing is more difficult to define and hard to identify (Broad 1981; Editorial 2005; Smolčić 2013; Ding et al. 2020). That is, most journals don't have specific definitions of salami slicing, and there're certain cases where salami slicing is allowed to a small extent (but how small is small?). For example, in highly integrated studies involving independent evaluations over multiple years and/or different laboratories studying distinct data sets, it may be reasonable to publish two or more papers with different data sets, especially if the one doesn't depend on the other. There's a fine line in making such judgments and requires experience, so it's always good to discuss these with your supervisors and senior coauthors in advance.
Consider and discuss authorship in advance. Any person who has made important contributions to the scholarly content of the study/paper should be included in the author list, while any person who hasn't made important contributions should be added in the acknowledgements (if agrees) but not in the author list (Schofferman et al. 2015). Before inviting colleagues to coauthor, read the journal's guidelines regarding authorship. Bear in mind that ensuring the study's funds with no further intellectual contributions to the production of the study/paper does not justify authorship, even if this is your supervisor. Furthermore, if you're a student, inviting an expert in the field to become coauthor to your paper may not be a good idea unless your supervisor has agreed or instructed to do so. If you invite others to be coauthors from early in the process, clearly explain what contribution you do expect from them, potential timelines (when do you expect to have their feedback back), and whether you have the agreement of your supervisor. Lead scientists are extremely busy and the least they want is to engage in a situation where they'll have to guide you in how to write a paper (this is your supervisor's responsibility). To facilitate their work and maximize the benefit from their involvement, send them a tidy and clean draft after receiving the approval of your supervisor. Likewise, it's good to discuss the process with your supervisor from the very beginning; however, try to do a good work (at the best of your ability) before sending him/her a draft. I suggest to avoid sending him/her a draft expecting that he/she will write your paper. This may show unprofessionalism, lack of motivation, incompetence, irresponsibility, and lack of desire to develop professionally.

When examining the authors' list, I suggest to visit the author guidelines of your target journal, which will likely state specific requirements regarding authorship. For example, Global Change Biology instructs (author guidelines, ${ }^{11}$ accessed on 10 August, 2021): "The list of authors should accurately illustrate who contributed to the work and how. All those listed as authors should qualify for authorship according to the following criteria: (1) Have made substantial contributions to conception and design, or acquisition of data, or analysis and interpretation of data; (2) Been involved in drafting the manuscript or revising it critically for important intellectual content; (3) Given final approval of the version to be published. Each author should have participated sufficiently in the work to take public responsibility for appropriate portions of the content; (4) Agreed to be accountable for all aspects of the work in ensuring that questions related to the accuracy or integrity of any part of the work are appropriately investigated and resolved; and (5) Contributions from anyone who does not meet the criteria

\footnotetext{
11 https://onlinelibrary.wiley.com/page/journal/13652486/homepage/ forauthors.html
} 


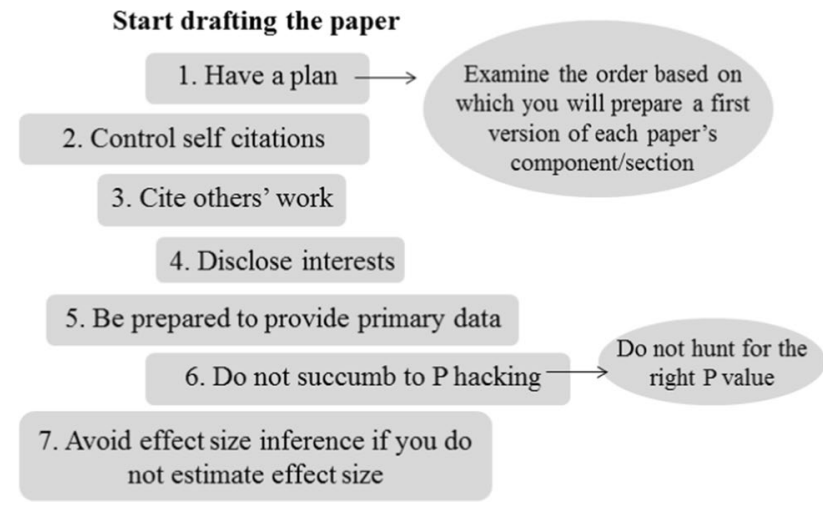

Fig. 2 Tips to consider when drafting the paper

for authorship should be listed, with permission from the contributor, in an Acknowledgments section (for example, to recognize contributions from people who provided technical help, collation of data, writing assistance, acquisition of funding, or a department chairperson who provided general support). Prior to submitting the article all authors should agree on the order in which their names will be listed in the manuscript." You may also read the author guidelines of other journals (especially published from different publishers) to get a better picture. For example, a plethora of journals mandates the inclusion of a statement explaining each author's contributions, while many journals recommend or require the use of relevant authors' roles listed by their publishers (e.g. Elsevier's CRediT roles ${ }^{12}$ ). You may also want to have a look at the guidelines developed by the International Committee of Medical Journal Editors (ICMJE), which is well known for its authorship criteria in sciences (http://www.icmje.org/), e.g. its Recommendations for the Conduct, Reporting, Editing, and Publication of Scholarly Work in Medical Journals (December, 2019; http://www. icmje.org/icmje-recommendations.pdf). I suggest doing these so to be educated before discussing authorship issue with others.

\section{Start drafting the paper}

Now that you've mastered the preceding points of consideration, it's the right time to start drafting your paper (Fig. 2).

\section{From where to start drafting my paper?}

Have a plan. You may consider the following protocol:

\footnotetext{
12 https://www.elsevier.com/authors/journal-authors/policies-andethics/credit-author-statement
}

- Leave conclusions section of the main manuscript and abstract for later, after drafting all the other sections of the main manuscript.

- If you have a title in mind, write it down first. I'm confident that you'll have more ideas about candidate titles and, thus, you can improve or change it several times during your writing. Title is the first thing people will read, including editors and yourself each time you open your document to work (at least in Windows' document management software). Hence, it's important to have an attractive title, but without deviating considerably from your data. Why should people read your paper among an extremely abundant and continuously-growing literature? You'll often find yourself listing a couple of candidate titles. Keep them there till the very end. If you've completed drafting the paper and are still unsure which to use, you may consider asking for the opinion of a colleague.

- Then, you may draft a first 'lose' version of the Introduction. While working on the other sections, go back to the Introduction each time you visit your manuscript for potential improvements. You'll find something to edit almost always. This will help you to maximize the quality of Introduction as you'll also have a better comprehension of your own data and results, especially in highly-integrated original researches with a broad data set. While discussing your results, and searching for literature, you may generate new ideas that can help to increase the significance and expand the scope of your Introduction.

- Continue with Materials and Methods (the section's name may differ in some journals). Explain the entire methodology in sufficient detail such that anyone can repeat the study with your very protocol/methodology. However, leave the sample and data collection and statistics section for later.

- Then, continue with data analyses. For each data set you analyze statistically, go back and fill each of the left subsections of Materials and Methods; describe sample and data collection and statistics section. Then, create the display elements and write also the results in the Results section. Continue with the next data set.

- When you finish, write the discussion.

- It is now time to write the conclusions. Do not repeat the results in the conclusions. Instead, provide a clear take-home message, one you would like readers to remember. This is a good place to clarify how your study advances the current scientific understandings of this subject. Try to put them in a broader context. Why are they so important? However, stick onto your data and write only based on what your data can support.

- Complete the writing by drafting the abstract. The next component to read after someone has seen the 
title and became curious to know more about your study is the abstract. Try to write an efficient abstract so to attract the reader to explore the full paper. Don't repeat the conclusions you wrote in the main paper. Be different. Write one-two brief sentences with the background to set the scene; this may be unnecessary in some cases, e.g. in very specialized journals (know your readership). Make it clear why you conducted this research and why now. Briefly explain the methodology (what you did) in one-two sentences. Follow up with the most important results in terms of novelty, occupying 3-4 sentences. Then, continue with some concise discussion of the results to help the readers understand why your results are important and how they add to the existing scientific base (2-3 short sentences). This is a general structure based on my own perception, personal preference, and experience, and is only indicative. However, what one should keep in mind is to keep harmony. As a reviewer and editor, I often come across abstracts whose background and/or methodological information occupies $50-75 \%$ of the total length, leaving relatively very little space for discussing the results. This would be less effective. All journals have specific requirements of the permitted size of abstract, but for original research articles the abstract is generally restricted below 300-350 words, for some journals even below 150 words. Furthermore, several journals require following a specific structure of abstract. Therefore, read the journal's guidelines regarding abstract before starting to draft the abstract.

- If you've not done it yet, select keywords. Most journals permit listing up to five keywords. Try to include the maximum allowed number because efficient use of keywords can help your paper being traced by more people. I suggest avoiding using keywords that are already included in the title and abstract because key search engines of scientific literature consider abstract and title in their search. Alternative, synonyms or alternative names of the same words can be used. Again, the publication practices are so relative that there is no standard protocol prototype. Hence, there're journals enforcing their own requirements for keywords. For example, some journals require the use of 5-10 keywords selected from the browser list of the US National Library of Medicine's Medical Subject Headings (MeSH; www.nlm.nih.gov/ mesh) (e.g. Elsevier's Plant, Cell \& Environment). Therefore, check the journal's author guidelines regarding keywords.

These suggestions mostly concern original research articles, the most common type of articles, and are based on my own personal experiences and professional development (my writing practice has changed over the years/with increasing experience, so will yours). These tips may serve as a good starting point, and you may expect that you'll develop your own writing "protocol" over time. Consider also that there're journals nowadays that publish research data (e.g. MDPI's Data and Elsevier's Data in Brief) and protocols and methodologies (Elsevier's MethodsX and Mdpi's Methods and Protocols). It may be good to consider from the beginning these supplementary options for facilitating reproducibility and enhancing the visibility of your data and protocols and methodologies. Many journals ask during submission whether you submit these pieces aside your submitted manuscript.

\section{Control self-citations}

Avoid heavily citing yours and your coauthors' papers. Excessive self-citations is a phenomenon widely occurring in the scientific literature, and early-career scientists show a tendency to have greater self-citation rates due to the so called 'youth effect', i.e. their published papers had little time to receive massive citations from other scientists (Van Noorden and Singh Chawla 2019). Excessive self-citing isn't an issue for scientists at the very beginning of their career, e.g. university students of various academic degrees who are writing their first articles. However, you should be better aware of the issue in order to avoid such potential practices of unwarranted references by your coauthors. Articles including your coauthor(s) in the authors' list that do not add to the scholarly content of the article should not be cited. I opine that science shouldn't be shaped within 'wooden' frames, but it should be 'plastic' so to provide higher degrees of freedom (flexibility) within certain relative limits. So should the scientific publishing be. That is, there're cases where relatively more self-citations may be acceptable, such as when describing methodologies that you've developed or importantly modified and/or if you're working in an emerging and rapidly-advancing research area where your papers cited to support the scholarly content in your new article cannot be replaced by non-self-references.

\section{Cite others' work}

Authors cite references not only when they refer to data and findings, but also when it comes to concepts or ideas reported in or developed based on other papers. If you've developed an idea based on a paper you read, give credit to those authors by citing their work to show that your idea is based on their work. If their work has helped you in any way in your own paper, give credit to their work. Don't search to cite references from only your own colleagues, teachers, or other scientists in your own country. Do cite international references based on proper literature survey, scientific merit, relevance, scholarly contribution to your paper, and being 
up-to-date. Massive citation of papers from your own country would add a nuance of rather local interest and lead to desk rejection of your paper due to lack of international interest. Cite references immediately when you are facilitated from them so to not forget later.

\section{Disclose interests}

If you or your coauthor(s) have any conflicts of interest, this should be disclosed. Add a relevant statement in your manuscript, usually placed after the main text and before your reference list. To this end, ask all your coauthors to disclose potential conflicts of interest. As a definition, conflict of interest is "a conflict between the private interests and the official responsibilities of a person in a position of trust" (Merriam-Webster Inc.). What may constitute conflict of interest is usually explained in the author guidelines, but you may read further information on the website of other bodies, such as of COPE, the World Association of Medical Editors, and the International Committee of Medical Journal Editors; you may also want to read some relevant publications to develop a more comprehensive understanding of the issue (Klein and Glick 2008; Ruff 2015; Dhillon 2021). Acknowledge any person, body, or institution that has helped you by any means in the acknowledgements section that is usually placed on the title page or at the end of the main text (before reference list) as indicated in the journal's author guidelines. Don't add thanks to reviewers and editors, however, unless they've helped you generate new ideas, perform new data analyses, and thus lead to considerably different results and conclusions. It's the job of editors to handle your paper in the best possible way and the responsibility of reviewers to conduct a high-quality review (if they have accepted to review). Both editors and reviewers know that you're thankful if you've improved your paper based on their comments and suggestions. I've come across new submissions whose acknowledgements thank reviewers and editors for their "helpful comments and suggestions" in a kind and polite manner. It's understood that you appreciate their efforts however, you don't know that they'll provide helpful comments and suggestions. Moreover, personality traits and behavior, and thus perception of others' behavior, highly vary among people. Hence, your practice may be perceived by someone as an effort to manipulate reviewers' and editors' judgment. By some others it may be considered flattering, and for some people this may not be perceived well; e.g. you may recall the famous quote "it is better to fall among crows than flatterers; for those devour only the dead-these

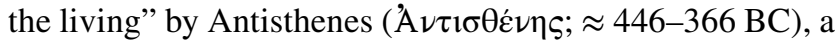
Greek philosopher and Socrates' pupil. For all these reasons, unless there are specific needs following review and revision (a rare case), refrain from adding thanks to reviewers or editors in your manuscript. Some journals also clearly indicate that "thanks to anonymous reviewers are not appropriate" (Global Change Biology, author guidelines, ${ }^{13}$ accessed on 10 August, 2021).

\section{Be ready to provide primary/raw data}

Be prepared to provide any original data that might be requested at some point of the peer review. This may be the case for articles not reporting primary data (e.g. reporting transformed data). If you're asked to provide them in the framework of a revision of your paper and instead you withdraw your paper, it's a bad sign and will raise concerns of ethical conduct. This is a situation that nobody wants to face in her/his career. Primary data facilitate cumulative science, and many journals mandate their providing along with the article. Even if a journal doesn't mandate making primary data available, keep in mind to provide them (at least arithmetic means with a measure of dispersion and sample size) in supplementary materials if possible. Primary data have multiple roles and can help saving resources, e.g. other authors may optimize their experimental design based on your data.

\section{Do not succumb to $P$ hacking}

The value of probability $(P)$ is obtained from statistical testing of a null hypothesis $\left(\mathrm{H}_{0}\right)$ and, in simple terms, indicates the odd for results equally or more extreme than the actual observations given that $\mathrm{H}_{0}$ is true. A survey of biology's literature would suggest that the results and conclusions of a tremendous portion of original research papers is based on $P$ value. $P$ value, however, is also one of the most discussed issues in the modern statistical and biology's literatures due to various misconceptions regarding its use, meaning, and inference. You may want to read some key papers on the topic so to become knowledgeable and avoid such misconceptions (Berger and Delampady 1987; Senn 2001; Connor 2004; Cumming et al. 2007; Goodman 2008; Lew 2012; Nuzzo 2014; Amrhein et al. 2019; Agathokleous and Saitanis 2020). The commonly-used level of significance is alpha $(a)=0.05$, although recent advances suggest that testing at the levels of significance of $a=0.005$ or 0.001 would decrease the level of non-reproducibility of scientific research by a factor of $\geq 5$ (Johnson 2013).

$P$ hacking is the phenomenon of mismatch between reported and actual $P$ values (Nuzzo 2014; Veresoglou 2015), and one that I have encountered numerous times as editor and reviewer. Studies with multi-factorial designs (e.g. including three- or four-way analyses of variance)

\footnotetext{
$\overline{13}$ https://onlinelibrary.wiley.com/page/journal/13652486/homepage/ forauthors.html
} 
Fig. 3 Tips to consider when you have a first draft ready
When you have a first draft ready

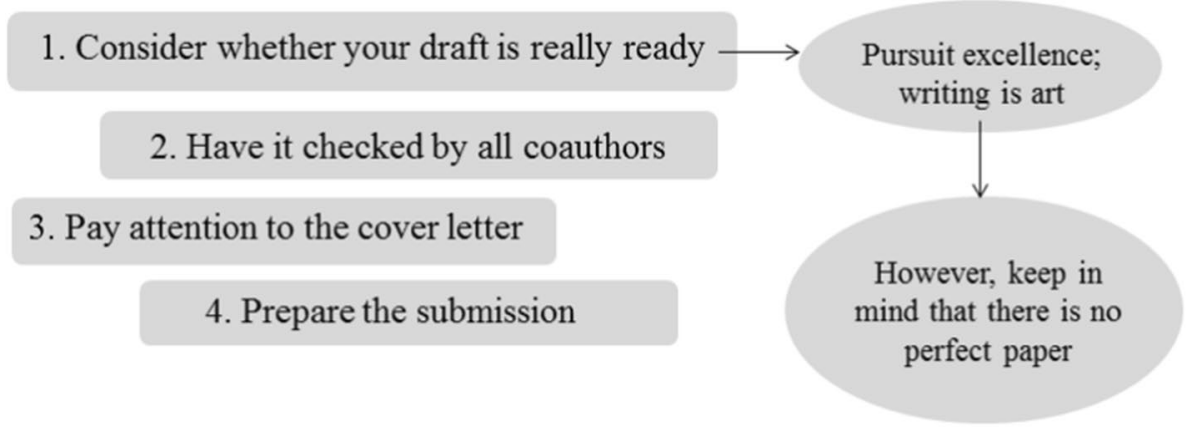

may be more prone to $P$ hacking, especially if using tests for multiple comparisons among means or multiple t tests without treating $P$ value. If one uses the common $a$ level of 0.05 (nominal) for comparisons, the rate of false rejection of a true $\mathrm{H}_{0}$ (type I error) is inflated, a phenomenon termed 'experiment-wise error rate' (Iglewicz 2014). While there are also other techniques to treat experimentwise error rate, Bonferroni correction has been widely used due to its ease, albeit it's conservative, giving the maximum error rate (Freund et al. 2010; Armstrong 2014; Veresoglou 2015). Let's say you have 15 comparisons. The probability that one or more $\mathrm{H}_{0}$ is falsely rejected equals to $1-(1-\alpha)^{\mathrm{n}}$, where $a=0.05$ and $n=15$ in this case. Solving the equation, the probability is $53.7 \%$. If $n$ were 50 , the probability would become as high as $92.3 \%$. Hence, it's quite clear that the probability to incorrectly reject $\mathrm{H}_{0}$ can be alarmingly high in studies with increased numbers of comparisons. In such cases, failure to treat experimentwise error can lead to incorrect results and conclusions. Even where there aren't so high numbers of comparisons/ tests (e.g. $22.6 \%$ for 5 tests/comparisons), significant differences at $a=0.05$ may be incorrectly presented if no treatment of experiment-wise error is applied (Veresoglou 2015). Using Bonferroni correction, one can easily treat experiment-wise error by dividing the $a$ level with the level of tests/comparisons, i.e. $a=1-(1-P)^{1 / n} ; P=0.05$ and $n$ is the number of tests/comparisons. In simple words, if you have 15 tests/comparisons, you use a level of significance of $a=0.0033(0.05 / 15)$. It's good to be aware of these issues because the current peer-review system may not permit their identification during peer review (Wehrden et al. 2015), and to avoid adding to the existing issue of most published research findings being likely false (Ioannidis 2005). As an additional suggestion, don't conduct tests until you obtain the $P$ values you want to find the differences you expect (Masicampo and Lalande 2012).

\section{Avoid effect size inference if you do not estimate effect size}

An often encountered important issue is claiming size of differences in the absence of relevant mathematical/statistical support. For example, a common misconception I frequently encounter in the biology's literature (and as reviewer) is the claim of relative differences based on differences in the $P$ value. For instance, one author may claim that chlorophyll content is a more sensitive biomarker of stress in some tested plants than superoxide dismutase because the difference in the chlorophyll content between treatment and control group was significant at $P<0.001$ while the difference in superoxide dismutase was significant at $P<0.05$. Another example is when one ranks the susceptibility or tolerance of organisms based on $P$ values. Red flag. This is a serious misconception as $P$ values don't support inference related to size/magnitude of differences, which would require the use of mathematical estimation of effect sizes for comparing magnitudes (Connor 2004; Agathokleous and Saitanis 2020). There're various effect sizes and complementary reporting indices that can be used (Breaugh 2003; Kirk 2007; Nakagawa and Cuthill 2007; Durlak 2009; McGough and Faraone 2009; Berben et al. 2012; McCabe et al. 2012; Sullivan and Feinn 2012; Lakens 2013; Tomczak and Tomczak 2014); however, their analysis is beyond the scope of this article. Now that you're aware of this issue, you can do a comprehensive reading of some key references cited herein and others if you're interested in estimating or mastering effect sizes. There're also available computerized applications that can help you make the estimations easily (see freely available electronic supplementary materials in Agathokleous and Saitanis (2020) and also https://www.cem.org/effect-sizecalculator). 


\section{When you have a first draft ready (before submission)}

\section{Keep in mind that there is no perfect paper}

Now you have your first draft ready and are excited to submit as soon as possible, right? I don't want to disappoint you, but you definitely haven't. Now you've the main base of the article upon which you'll build (Fig. 3). Writing is art. It takes time, and requires attention to the finest details. A painting is never perfect. Hence, keep in mind that your paper will never be perfect. If you critically examine any paper in any published journal, you'll commonly find at least a couple of minor non-scholarly-content 'errors' in each. There is always space for improvements, and editors know this very well. Does this mean that you'll be improving your paper to the infinite? Apparently not, and a cost-benefit assessment is needed. You may want to stop working on small details when you realize/feel that the time (and effort) you spend outweighs considerably the benefit of the paper from your edits. For beginners this may be hard to define, but later on you'll see that this point is clearly understood. If you've no coauthor, don't worry. If you're 'lucky' to receive good review reports, you'll still have the opportunity to apply further improvements based on reviewers' suggestions. If you've coauthors, the most likely scenario is that you'll thoroughly revise the paper based on your coauthors' comments and suggestions.

\section{Have it checked by all coauthors -the importance of corresponding author}

Before sending the paper to coauthors, it may be beneficial if you ask some senior members of your lab/team to provide you with a feedback. Thank them and avail of their comments to potentially further improve the paper. Then, send the paper to all your coauthors; however, communicate with your supervisor first because he/she may instruct you otherwise. For example, your supervisor may want to work first with your draft in order to improve it considerably before sending it to other coauthors. This is his/her responsibility if (s)he is coauthor, and especially if (s)he is also corresponding author, of your paper. If (s)he is corresponding author, (s)he is also responsible for all matters of communication regarding this paper, including communicating with all authors, submitting the paper and interacting with the journal editors, responding to reviewers (but note that you're encouraged to try preparing the response letter first for your training) as well as to readers of your paper following its publication. During the process of interacting with colleagues about your paper, remember to express your gratitude to all those who have contributed to your paper by any means.
Who is gonna be the corresponding author is also an important matter, especially because it can have an important impact on someone's career. Remember that journals find reviewers from published literature, typically the corresponding authors. Furthermore, the corresponding author is the one who will interact with readers and journal. Hence, being corresponding author of papers can enhance one's reputation and international visibility, and you should examine the issue of the corresponding author early in the process of determining authorship. For example, if someone has never been designated corresponding author on papers, journals won't invite him/her for reviewing papers ${ }^{14}$ and, thus, would barely become academic editor of scientific journals. However, if you're a student enrolled in a BSc or an MSc degree or a PhD student who doesn't wish to continue a research or academic career, it may be more appropriate to indicate a senior coauthor as corresponding author who guarantees readiness to respond to any requests regarding matters related to the article for a relatively long time. If you're an early-career researcher or academic (e.g. lecturer or assistant professor), I don't see any reason justifying not being corresponding author of your paper. As the lead author, there should be nobody knowing the paper's content better than you. Hence, I opine that marking someone else as corresponding author might look as if you were unable to manage responsibly any arising matter. The issue of corresponding author, however, should be examined with reference to the specific journal's guidelines, considering that there're journals that don't allow the designation of more than one corresponding authors, such as the Journal of Hazardous Materials (author guidelines, ${ }^{15}$ accessed on 10 August, 2021).

\section{The cover letter}

While waiting feedback from colleagues and coauthors, utilize the time to prepare an excellent cover letter, which the vast majority of journals require upon article's submission. This is your last chance to convince the editors that they should consider your paper for potential publication in the journal. Consider the below points:

- When you've the article ready for submission and preparing the cover letter, it's time to visit the author guidelines once more. Check the requirements for cover letter. Many journals have specific requirements of what to include or not include in the cover letter. Confirm that you comply with the guidelines.

\footnotetext{
${ }^{14}$ Unless proposed by supervisors or other colleagues, and, even in this case, competent editors might hardly consider them for reviewers.

15 https://www.elsevier.com/journals/journal-of-hazardous-materials/ 0304-3894/guide-for-authors
} 
- With the current editorial practices and the often multiple Editors-in-Chief and many Associate Editors, it's okay to address the letter to 'editor' in general. The editor who has handled a paper, however, is commonly indicated in the decision letter, especially if the paper is given revision or is accepted. If you get a signed revision letter or the editor's name is specified, it might be preferable to address the letter to the specific editor.

- Mention the article's title and authors, and confirm that you haven't published or have under consideration for publication elsewhere this work in part or fully in English or other language. State that all authors have read the manuscript under submission and agreed with the submission (make sure you did this).

- If you or some coauthors have a conflict of interest to declare, expose it clearly in the cover letter. If you haven't any, indicate it in a concise statement.

- State whether you've uploaded your paper already on a preprint server or specific website. This is important to avoid incorrect rejection based on potentially misinterpreted and non-properly-checked similarity check.

- If this is a resubmission of a previously rejected paper, clarify this (state the previous manuscript number and title) and explain why you resubmit (what have you changed) and if the previous editor encouraged resubmission.

- Stress out briefly the scope, novelty, and impact of the paper (Lowry et al. 2020). Don't copy the abstract or conclusions of your paper. Avail of this opportunity to communicate some more information to the editors and convince them that they should consider publishing your paper. Be brief and direct, within one or two short paragraphs. Don't write a pages-long cover letter. Keep it formal and signed, including all the information of the corresponding/submitting author.

Include suggested and, if needed, opposed reviewers (Grimm 2005) in the cover letter along with contact information, their institutional details, and a justification of why you propose or not propose them. Most journals require inputting this information in the submission system, but it's good to also include them in your cover letter for the editor's attention. Who to suggest? Definitely not your classmates, teachers, or relatives. You had better to discuss this matter with all coauthors, if there're any, and have the consensus of all authors based on mutual understanding. It's important to ask your coauthors because they may have reasons to suggest opposed reviewers, and recommending or opposing reviewers can facilitate publication of your paper (Grimm 2005). In general, candidate reviewers are people who have important experience in the paper's subject, as documented by peer-reviewed papers, and who aren't close collaborators. In no way you should contact people asking them to review your paper if they're approached by the journal; this may be perceived in a bad way, especially if you haven't even met someone. This applies to requesting review comments on your paper prior to submission since peer review takes much time and effort.

\section{Prepare the submission}

When there is a consensus among all authors that the manuscript is ready for submission, there you go. Some points for consideration:

- Register on the journal's online submission system if you aren't registered already. Use an email address that you routinely check, and add the journal in the safe senders so to avoid important messages ending up in your spam emails folder that might hamper the peer review process.

- Some journals request that you select a handling editor and/or editorial board member. If this is the case, check the journal's website with the editors. If you're unfamiliar with the editors, make a survey to find editors that are most closely related to the subject of your paper.

- Prepare the figures' and tables' high resolution files for uploading, although many journals don't require this upon the first submission nowadays.

- Unify the reference and citation style across the manuscript, and correct any errors. Many journals don't mandate the use of a specific reference and citation style upon the first submission, but they highlight the need for consistent style. I strongly recommend the use of some reference management software, among the many existing (e.g. Mendeley, EndNote, Zotero, MyBib, Qiqqa etc.). This is particularly useful when you 're submitting to a journal requiring the use of numbered references. It can protect you from errors introduced when one manages the references manually, especially when there is a heavy list of references and a lengthy main text, as is the case of critical literature reviews. Using reference management software reduces the odds of introducing errors when revising the paper.

- Confirm that you've numbered the pages and line numbers (continuous numbering). While the former may not be required in the author guidelines of the target journal, it can facilitate reviewers and editors. Note also that many journals add line numbers to your submission when you upload your manuscript. As reviewer and editor, I found myself disliking this automated insertion in some journals because the line numbers restart at each page and each number doesn't necessarily indicate a specific line (not aligned with the text). This situation makes the job of reviewers, editors, and even authors (when addressing reviewers' comments) more difficult; pennies on the dollar. Therefore, I suggest paying some attention 
Fig. 4 Tips to consider after the original submission

After submission

1. Pursuit aretê during the entire process

2. Keep all coauthors in the loop

3. Consider the time needed for the first decision before contacting the journal's office

4. Know what the various manuscript statuses mean

\section{Know the different types of} decisions

What to keep in mind when dealing with reviewers

to the line numbers when you check the submission pdf for approval. What I sometimes do is to add continuous line numbers, even if the journal does add the aforementioned type of line numbers, and confirm that the line numbers I've added are clearly visible (let the automated numbers be there too).

- Confirm the theme fonts, font size, page margins, and line and paragraph spacing, although they're less important. The most important among these may be the line and paragraph spacing, but the most commonly used is 2.0 points.

- Before approving the submission pdf, check it carefully. You may want to send it to your supervisor and other coauthors for an additional check, especially if you're a beginner. Your senior colleagues may easily notice an error based on their experience.

- Approve the submission.

\section{After submission}

\section{Pursuit aretê during the entire process}

You've now proudly approved the submission and, thus, your precious paper has been submitted. Good luck, although you'll barely need it if your work is scientifically excellent and your paper of high quality. This will likely give you much satisfaction since it may reflect the outcome of efforts lasted for some years, spanning from designing your research to executing it and finally writing the paper. But this ain't mark the end (Fig. 4). Instead, you've just entered the publication arena. Congratulations. You should now be prepared for the 'battle' — but a gentle battle without fighting. Remember that scientists should pursuit aretê ( $\alpha \rho \varepsilon \tau \dot{\eta}$ in
Greek; a general translation in English is virtue), i.e. ethical/ moral excellence or supremacy (Yiaslas 2019).

\section{Keep all coauthors in the loop}

Keep your coauthors posted about submission-related matters, and do this without delays - they've the right to know too. Don't they? As soon as you've approved the pdf and completed the submission, write to your coauthors, even if many journals send automated submission confirmations to all authors. Let them know that you've submitted the manuscript and thank them once more for all their contributions. Even as a beginner you may not realize it, even small additions/edits to the manuscript can make a huge difference in the outcome of the peer review. Attach also the final submitted files and submission pdf for their record. Be aware that academic scientists have evaluations and may need such a proof. Independently of this, all coauthors have the right to have all the materials at any stage in the process. When you receive the decision letter, forward it to them, and don't forget to attach any documents uploaded by reviewers and editors.

\section{How long should I wait for the first decision?}

You may receive a decision on your manuscript from within a few hours to several months. There're numerous factors that can affect the peer review time. For example, it depends on the journal where you submit. If you submit to broad multidisciplinary publications (e.g. Science, Nature) with low acceptance rates, the chances for obtaining a fast desk rejection within hours are high. This, however, may also be the case for top specialty journals (e.g. specialized in Forestry, Environmental Science, Ecology, etc.) with relatively 
low acceptance rates as the academic editors often reject papers right away based on their own publishing agendas.

Let's say your paper is plagiarism-free, has a quite low similarity, isn't a duplicate submission, doesn't contain unethical practices or striking issues with statistics, amongst others, and is rather excellent. However, it's still desk rejected. Don't be discouraged. The best-laid plans of mice and men oft go astray ${ }^{16}$ (no matter how well you're prepared, the outcome may not be what you expected, at least temporarily). This is how the publishing business works. Remember that there are thousands of scientific journals nowadays, and their loss means gain for another journal. Journals have their own agendas and your paper may simply not align with their current publication policies. In journals where the publishing space is much smaller than the number of submissions in a year, editors may prefer to publish content that is considerably different from what they've recently published or planned to publish, or they may simply think that your paper isn't among the most competent or competitive from those they have in hands. When these are at play, you may hear back within hours. If your paper is rejected based on issues with its scholarly content that have been determined by editors, you'll still hear back within a few days. Many journals give from 3 to 7 days to editors to act on your manuscript. However, there are often 2-3 editors sequentially assigned to your paper, and this timeframe may apply to each of them. Therefore, if your paper is rejected by editors without external peer review, you'll commonly be informed within a few hours to about 3 weeks. If you check the submission system after several weeks and see that the paper is still with editor, you may want to contact the editorial office of the journal (not academic editors) to politely ask what the status of your paper is. Remember that most journals are businesses and you're the customer. They make profit thanks to you. Therefore, they should responsibly address all your concerns.

If your paper makes it to external peer review, congrats. You've convinced the editor that your paper merits consideration for publication to the journal, and made it to the next step. Note that passing the 'guard' of editors is often a difficult point in lead journals with relatively low acceptance rates. Reviewers are usually given from 10 to 21 days to submit their review reports, although there're still journals that give even about two months. So, it's good to explore the indices of publication speed of the journal when you're in the process of selecting a journal.

If your paper was sent to reviewers (under review) in time and you're waiting for the decision, be patient. I advise against contacting the journal if 3 months haven't passed since the submission. This time window is reasonable

$\overline{16}$ Idiom likely adapted from Robert Burns, 18th-century poet. based on my experience as author, editor, and reviewer of hundreds of papers and many dozens of journals. Patience doesn't harm. If you're checking the submission system all the time, you simply waste important time. It's fine to check from time to time (e.g. weekly) but don't be obsessed and repeat it every some minutes. Likewise, I suggest avoiding sending emails to editors and journal office all the time. For more experienced authors, if you're a reluctant reviewer who doesn't respond in time, and may not submit review reports on time, you may not expect that others will do otherwise for you. In general, editors and journals may want more than you to have a quick decision back to you, as the journal indices can be affected, which in turn may affect authors selecting the journal, and, thus, their business. Keep in mind, however, that how fast the decision is made depends upon reviewers. Reviewers are busy, and reviewing is a voluntary commitment requiring much time. Therefore, the editors may need to contact numerous reviewers until they rope in the required number of referees. Some of them may never submit their review report or submit it late. In some other cases, you may think that the editor is delaying your process, whereas in fact he/she is trying to help you. For example, the required number of review reports might have been obtained, and some of the reviewers recommend rejection, while the editor has a different opinion. This can lead the editor to seek recommendations from additional reviewers, extending the time of peer review.

As a general tip, I suggest that there is no need to be anxious and contact the journal as long as you see that the date of manuscript status changes from time to time. No noticeable change in the manuscript status' information, however, doesn't mean no actual change. For example, an editor may be exchanging correspondence with other editors or even with reviewers outside the online submission system. Remember the Heraclitus' quote "no man ever steps in the same river twice, for it's not the same river and he's not the same man" (things that may seem constant may be actually undergoing change).

\section{What do the various manuscript statuses mean?}

There are various statuses of manuscript peer review stage in different submission systems and journals. The most common $\operatorname{are}^{17}$ :

\footnotetext{
17 These are status names used by JFR too. The name of each status can differ with journals. For example, (i) Manuscript Submitted may be same with Undergoing Initial Checking, (ii) Reviewers Invited may be same with Reviewers Assigned, (iii) Under Review may be same with Awaiting Reviewer Scores, Awaiting Referee Scores, and Manuscript Assigned to Peer-Reviewer/s (iv) Required Reviews Completed is same with Reviews Completed, and (v) Decision in Process may be same with Under Editor Evaluation, Pending Recommendation, Awaiting AE Recommendation, Awaiting EIC Decision, and Ready for Decision.
} 
- Manuscript submitted: Your manuscript has been received by the editorial office. It will now be subjected to technical checking and then assigned to an editor. If the journal office wants you to solve some technical issues, the manuscript will be returned to you. Commonly, you'll be able to edit your existing submission in the system, meaning that you shouldn't submit it again as a new submission. Read carefully the information in the email you've received; there will be specific instructions.

- Editor invited: An academic editor has been invited to manage your paper. The editor hasn't yet agreed to take on the assignment. This stage is used less frequently.

- With editor: Your manuscript has been assigned to an editor. The editor was previously invited and has agreed to manage your paper, or he/she was assigned directly to your paper without being asked to agree or not. Your paper has commonly been assigned to a senior editor first. The senior editor can assign the paper to an equalor lower-rank editor, who in turn may assign the paper to a further equal- or lower-rank editor. Depending on the parameters set in the journal's submission system, you may see changes in the status date while the manuscript status name remains same. If the journal indicates the time of status date too, the status time can change one or more times within the same day, wherever a new editor is added in the loop. Authors commonly don't notice this change since they've better things to do than checking the system every some minutes. If a journal displays only the date of status (time isn't indicated), no change in the status date will be made if all editors are added in the loop on the same date. If, however, this activity takes place on different dates, the status date will change while the status name will remain same (i.e. with editor).

- Reviewer invited: Reviewers (commonly $\geq 3$ ) have been invited to review your paper. None of them has agreed to take on the assignment yet. This stage is used less frequently.

- Under review: The paper is now under review. If the 'Reviewer Invited' status preceded, it means that at least one reviewer has agreed to review the paper. If the 'Reviewer Invited' status wasn't used, it simply means that invitations have been sent to reviewers, but you can't know if any of them has agreed to review your paper. If new reviewers are invited on different days, the status date will be changing. If these changes are noted within some days or the first few weeks of the submission, it commonly means that the editor couldn't ensure the required number of reviewers yet, but he/she is still working on this. In some journals, the status date for 'Under Review' can change when some reviewer submits his/her report or when the editor evaluates the review reports. A small "secret" is also that the required number of reviews might have been obtained but you didn't notice it because the editor has sent out new review invitations or has changed the parameter of required number of reviews to a higher number.

- Required reviews completed: The required number of reviews has been received, and the editor will go through the review reports and perhaps your paper. This stage may last from some hours to more than one week. Be patient, and avoid sending emails to the editor asking about the status of your paper. As an editor, I faced before this situation where an author of a paper has sent me such a correspondence within three days of this status's appearance (in 3-4 weeks from initial submission date). There are some reasons why you shouldn't disturb the editor or editorial office so soon after this status appears. You cannot find these reasons written somewhere, so I'll share them with you based on my own experience as editor. The status is quite relative, and doesn't necessarily mean that the review of your paper has been completed. The editor might have received the required number of reviews, but remember that this is the minimum number of required reviews, i.e. typically 2 or 3 . However, (1) there may be disagreement among the recommendations of the reviewers or (2) the editor may have a different opinion from some or all the reviewers, and (s)he may need more review reports. In this case, the editor may need some time to trace and invite other reviewers -remember editors have dozens of papers to handle, not only yours. When new reviewers are invited, the status will commonly change back to 'Under Review'. Alternatively, the editor (1) might have received the minimum number of required reviews but is waiting additional reports from reviewers who have agreed to review the paper but haven't submitted it yet, or (2) (s)he changed the parameter of the required number of reviews to a higher number, e.g. (s)he may initially expect 2 reports but later changed it to 4 reports. Another possible scenario is when a lower number of reports than the required might have been set, e.g. 1, while more review reports are expected to be delivered. In all these situations, the status can remain 'Required Reviews Completed', but as you understand now without meaning that the review of your paper has been completed.

- Decision in process: The peer-review of your article has been completed, and the decision letter will be emailed to you shortly. This stage can last from a couple of minutes to several days. At this point, there're two possible reasons: (1) at least one editor has submitted his recommendation/decision to the system or (2) the senior editor supervising the process (i.e. the highest-rank editor managing your paper) has started the process of submitting his/her decision. Once the senior editor has submitted the interim or final decision, the corresponding author who has submitted the paper will receive an email. It should 
be noted here that the senior editor may see things differently from a lower-rank editor, e.g. he/she may find the review reports insufficient, and can always invite more reviewers, which would result to the status changing back to 'Under Review'. This is a rare case, however, but not impossible. For example, the lower-rank editor may be a new editor with no extensive experience and may be trained by a senior editor who may supervise the process.

\section{I got the decision letter, now what? The different types of decision}

Following the aforementioned statuses, the final status would indicate the decision of the editor and can have all sorts of names indicating a decision status. Once you receive the decision letter, forward it to your coauthors, if any. There are various types of decision:

- Reject: Your paper has been rejected. Take it easy, this is how this strategy "game" works. You probably have received extensive comments from at least two reviewers. See this as an opportunity to improve your paper (Kotsis and Chung 2014). Read the comments once. Don't be embarrassed, get angry, or be ashamed of your work. Remember that even highly-talented authors and top scientists experience similar situations. Sleep on the comments for a few days; this will allow you to return to a homeostatic psychological state if you've been affected by the comments. Then, return to the comments, read them all in detail, and improve whatever can be possibly improved from those indicated by the reviewer(s). After improvement, turn to your supervisor and coauthors again (if any), and restart the loop of the paper submission process. This process is like a "for-do loop" repetition control structure in Pascal programming. You may need to repeat the loop a few times, and this is why I recommended keeping in mind 2-3 additional journals when selecting a target journal. Well, here there are a few further points to consider. Read carefully the decision letter. Does the editor write some comments? Does he/she state clearly or imply that you're encouraged to resubmit your manuscript as a new submission? Not all journals have a decision status for rejection and encouraged resubmission, and while the decision you got is 'reject', you may be given the chance for resubmission. If this is the case, make sure that you improve your paper considering all the reviewers' comments. If you resubmit, add a response letter in the cover letter. Copy all the editor's (if any) and reviewers' comments, and respond to each comment separately, explaining how you addressed or why not addressed the indicated issue. You may facilitate editor's work if you add a brief paragraph explaining the big picture of the main improvements you applied that make your paper meriting reconsideration. Another possibility is that you aren't encouraged to resubmit your work, but you want to write a rebuttal. Rebuttals are barely successful (Hites 2021) and are considered only in very specific cases, such as if it is clear that your paper was rejected based on incorrect criticisms. For example, your paper was rejected based only on one reviewer incorrectly criticizing that you had no sufficient number of replicated experimental units while you had clearly stated the replicates in the paper. If you decide to proceed with a rebuttal, write everything in the cover letter, as explained above. Don't enter into a personal debate with reviewers and start criticizing them. Remember that if a reviewer didn't understand something is probably because of your writing. Be thankful and try always to find ways to potentially fix each single issue indicated. If a reviewer hasn't understood something, other readers of your paper might also not understand. It should also be made clear that you aren't supposed to always agree with each single comment of a reviewer. Authors may think that they must do everything a reviewer says, but reviewers also may think that their job is to rewrite reviewed papers or see their selves as a teacher and authors as their students. It's okay to disagree with some comments, but this should be based on convincing reasoning-strong scientific support would help if it's about the scholarly content of your paper.

- Revise: You're getting closer to get your paper published, well done! The editor believes that your paper has relatively high odds to be published following revision. The revision can be minor, moderate, or major, and this is usually indicated in the decision letter and/or the manuscript status in the submission system. ${ }^{18}$ As a rule of thumb, minor revision leads to a quick acceptance, usually without sending the paper back to reviewers; however, this depends on how well the editor does his/ her job and sometimes on whether his/her expertise is relevant to your paper. Even if the revision is minor, I strongly recommend that you do an excellent and thorough work. Don't restrict yourself to simply correcting what the reviewers mention. Go again through the entire manuscript, and do this very carefully. There has been some time since you last read the manuscript, and you can now see things in a different way. ${ }^{19}$ Do not afraid or hesitate to apply changes. This is your last chance to apply important changes to the scholarly content of your

\footnotetext{
18 Minor revision can be termed differently, such as "Accept conditionally, minor revisions needed".

19 Note: I personally go back to the manuscript from time to time while it is under review and note potential changes to apply during revisions.
} 
paper. If it's to increase the quality further, it's worth taking more time to get published. A misconception I heard a couple of times is that you just do only what the reviewers say, agree or not, without applying other changes when the revision is minor so that the editor doesn't send the paper back to reviewers. Don't fall into the trap of putting yourself into wooden frames because no single policy/practice applies to every situation. If the editor is professional and does his/her job as is supposed to do, there would be no difference. But even if the paper is send back to reviewers, why not if it is to enhance its quality and avoid errors? This can help your paper and protect your reputation. Extending your revisions beyond the minor changes indicated by reviewers shows professionalism and responsibility in my view. All the additional changes, however, should be clearly communicated to the editor (in the response letter). Moderate revision is rarely used, and has no important difference from major revision in my view; it is quite arbitrary and based on editor's perception of what separates moderate from major. A major revision indicates that considerable changes would be needed to bring the manuscript to the level required by the editor to accept the paper, including modifications to the scholarly content, such as methods application and explanation, statistics, results interpretation, and/or conclusions. Thus, take the time needed to address all the issues in the best of your ability (see next section before revising your paper).

- Accept: You'll rarely receive this decision upon the first submission of your paper. The chances to receive it, however, increase if this is a first submission to a journal following improvement based on reviewers' comments after rejection from the same or a different journal. If your paper has been accepted for publication, congratulations, you made it! (Dollars to doughnuts that you're thrilled to receive this news).

\section{Prepare the revision and submit}

Make a plan of the revision as soon as you receive the revise decision. Be organized. Try to do your best in submitting the revised manuscript by the deadline indicated by the editor. If you think you need more time to complete the revision, contact the editorial office of the journal to extend the deadline. Things change and scientists are often extremely busy. Furthermore, you're the customer. Hence, it's fine to ask for an extension of the deadline, but when you do, indicate in your letter how much more time you think you need. If you have coauthors, keep in mind that they may be extremely busy too. Therefore, I recommend that you send them the revision materials much ahead of the deadline so to have several days to work with them. All of them would want to work on the revision carefully, thus give them the time to do this without putting them in a difficult situation. Remember that all authors should approve the revision for submission, and never ignore them-you may find yourself taking a turn in the barrel at some point. They should always be in the loop during the entire process.

Copy all the comments from editors and reviewers in a new document, so called response letter. Don't apply any changes to the comments, including correcting languagekeep them authentic. Below each comment explain how you've addressed the issue pointed out by the reviewer, or why you didn't do so. Your answer should be convincing, explaining in sufficient detail and supported by scientific references wherever needed. As I mentioned multiple times, there is no single practice applied to every situation. Some answers can be just one word, whereas other answers can be one or more paragraphs, depending on the context and extent of changes applied, if applied. As a general tip, try to be concise, direct, and always on the topic. Write not too much, not too little, just right. Be polite. Remember that reviewers voluntarily spend considerable time to review your paper for your own benefit-even if your paper is rejected, reviewers' comments can help to improve your paper almost always. While authors may come across personal attacks by reviewers, no professional editor who is doing correctly his/her job would allow this, and no reviewer has such a right (his/her call is to comment on the research itself and the quality of the paper). Not only such a practice by a reviewer is considered inappropriate, but it may also raise legal concerns. Editors should protect authors from such attacks, and can always request reviewers to edit their comments or even consider exclusion of the entire review report. If you face this situation, I suggest that you try to remain neutral and don't engage into debates at personal level-avoid emotional contagion, i.e. matching your emotional state with reviewer's emotional state (Pérez-Manrique and Gomila 2021). Inappropriate and unethical behavior of a reviewer can be stressed out in the response and/or cover letters, mentioning that it's outside science's spirit and ethics to enter into debates at personal level and, thus, you remain neutral in your responses. However, improve your scholarly content as needed and indicate this. You may also consider various options including (1) contacting the editorial office of the journal bringing into their attention the matter, (2) requesting withdrawal of your paper, and (3) communicating your problem to the COPE, although I suggest to turn to the editorial office of the journal before turning to external bodies such as the COPE. Finally, make the response letter user-friendly. Avail of available editing tools to make the response letter more pleasant and easier to reviewers and editors to follow. For example, you can use bold, italics, or underlining to stress out the most important points in each response. It's also helpful to reviewers and editors if you 
use different colors of fonts for reviewers' comments and your responses.

Cross-check all your revised submission components before approving the revised submission pdf file. After you complete the submission, brief your coauthors and wait for the decision. If the revision was minor, you may hear back within hours to some days (commonly up to one week). If it was major, you may expect to hear back commonly within a few days to some weeks (commonly 2-4 weeks); however, it may last longer.

Shortly after your paper is accepted for publication and is transferred to the publisher for production, you'll receive the proofs. Download the pdf of the proofs, send it to all the coauthors, and keep it in your record. You're usually asked to send any corrections back to the journal within $48 \mathrm{~h}$. Nevertheless, this is your last chance to apply any corrections, and, if you need some more time, ask for an extension of the deadline. Let them know you need some more time. At this stage, however, you shouldn't make any changes to the scholarly content of the article. If you need to do so, the permission of the academic editor who managed the peer review of your paper would be needed, and the publication of your paper may be delayed. Check the proofs carefully, and apply all the minor corrections needed. Your paper will be online soon after submitting the corrected proofs, commonly within one week. Many journals also publish manuscripts in their accepted form, often within 1-3 days from the acceptance.

\section{Consider serving as peer reviewer}

Now that your paper is published online, it's the right time to be prepared to act as a peer reviewer too, especially if you're designated as corresponding author. The referees of your paper have spent considerable time reviewing it, and you should consider doing the same for others. Author' and reviewer' roles are tightly linked, and acting as reviewer would improve your writing skills. How you can become a better reviewer is the subject of a succeeding paper (Agathokleous 2022).

\section{Conclusion}

In the pursuit of scientific knowledge, researchers engage in peer-reviewed publishing in a wide variety of scientific journals. In this piece of paper I provided a guide for peerreviewed publishing, which I hope it will help thousands of early-career research scientists and students at higher institutions to become more knowledgeable and familiar with the current peer-review system of most scientific journals. While your goal may be to publish your papers, have fun during the journey. At the end it's the journey that may matter more than reaching the destination (recall 'Ithaca', Constantine P. Cavafy's 1911 poem). Regardless of the outcome of your submissions, the entire process will make you wiser and more mature, knowledgeable, and experienced. I do hope that you enjoyed reading the paper and found it useful to improve your skills, and wish you all the best for your research, writing, and career ahead.

Note Because of the commentary-type nature of this paper, the author has often used informal language and idioms (except in the Introduction) to make the paper more entertaining and user-friendly. A formal tone is expected in the scientific writing, and you should refrain from using informal language and idioms when writing your research paper.

Acknowledgements The author is grateful to Dr. Damià Barceló, Professor at the Institute of Environmental Assessment and Water Research, IDAEA-CSIC, and the Catalan Institute for Water Research, ICRA-CERCA, Spain, for comments and suggestions on a preliminary draft. The author is also thankful to Dr. Lei Yu and the in-house editorial team of JFR for providing JFR's information as well as to Mr. Noboru Masui, $\mathrm{PhD}$ Candidate, for sharing some information about journal guidelines.

\section{Declarations}

Conflict of interest Any commercial name cited in this manuscript, e.g. of journal or software, is not for advertisement, and the author does not intend to recommend or encourage the use of their services. The views presented herein are those of the author/editor and do not represent views of the journal's editorial board as a unit, the journal's editorial office, the journal itself, the publisher, or the author's institution. E.A. is Associate Editor-in-Chief of this journal; however, he was not involved in the peer-review process of this manuscript. The author declares that there are no conflicts of interest.

\section{References}

Agathokleous E (2022) Engaging in scientific peer review: tips for young reviewers. J For Res. https://doi.org/10.1007/s11676-02101389-7 (In Press)

Agathokleous E, Saitanis CJ (2020) Plant susceptibility to ozone: A Tower of Babel? Sci Total Environ 703:134962. https://doi.org/ 10.1016/j.scitotenv.2019.134962

Amrhein V, Greenland S, McShane B (2019) Retire statistical significance. Nature 567:305-307. https://doi.org/10.1038/ d41586-019-00857-9

Armstrong RA (2014) When to use the Bonferroni correction. Ophthalmic Physiol Opt 34:502-508. https://doi.org/10.1111/opo.12131

Berben L, Sereika SM, Engberg S (2012) Effect size estimation: methods and examples. Int J Nurs Stud 49:1039-1047. https://doi.org/ 10.1016/j.ijnurstu.2012.01.015

Berger JO, Delampady M (1987) Testing precise hypotheses. Stat Sci 2:317-335. https://doi.org/10.2307/2245772

Böhme G, Stehr N (1986) The Knowledge Society. Sociology of the Sciences book series, vol 10. Springer, Dordrecht. https://doi.org/ 10.1007/978-94-009-4724-5_2 
Breaugh JA (2003) Effect size estimation: Factors to consider and mistakes to avoid. J Manage 29:79-97. https://doi.org/10.1016/ S0149-2063(02)00221-0

Broad W (1981) The publishing game: getting more for less. Science 211:1137-1139. https://doi.org/10.1126/science.7008199

Clark AM, Thompson DR (2017) Five (bad) reasons to publish your research in predatory journals. J Adv Nurs 73:2499-2501. https:// doi.org/10.1111/jan.13090

Connor JT (2004) The value of a $P$-valueless paper. Am J Gastroenterol 99:1638-1640. https://doi.org/10.1111/j.1572-0241.2004.40592.x

Covaci A, Nieuwenhuijsen M, He Z, Zhu YG (2019) A new era in the history of Environmental International. Environ Int 122:1-2. https://doi.org/10.1016/j.envint.2018.12.046

COVID-19 Host Genetics Initiative (2021) Mapping the human genetic architecture of COVID-19. Nat ure In Press. https://doi.org/10. 1038/s41586-021-03767-x

Cumming G, Fidler F, Vaux DL (2007) Error bars in experimental biology. J Cell Biol 177:7-11. https://doi.org/10.1083/jcb.200611141

Das N, Panjabi M (2011) Plagiarism: Why is it such a big issue for medical writers? Perspect Clin Res 2:67. https://doi.org/10.4103/ 2229-3485.80370

de Camargo Jr KR (2011) Science, knowledge, and society. Am J Public Health 101:1352. https://doi.org/10.2105/ajph.2011.300311

Dhillon P (2021) How to be a good peer reviewer of scientific manuscripts. FEBS J 288:2750-2756. https://doi.org/10.1111/febs. 15705

Ding D, Nguyen B, Gebel K, Bauman A, Bero A (2020) Duplicate and salami publication: a prevalence study of journal policies. Int $\mathrm{J}$ Epidemiol 49:281-288. https://doi.org/10.1093/ije/dyz187

Duggan F (2007) Plagiarism: prevention, practice and policy. Assess Eval High Educ 31:151-154. https://doi.org/10.1080/0260293050 0262452

Durlak JA (2009) How to select, calculate, and interpret effect sizes. J Pediatr Psychol 34:917-928. https://doi.org/10.1093/jpepsy/ jsp004

Editorial, (2005) The cost of salami slicing. Nat Mater 41(4):1-1. https://doi.org/10.1038/nmat1305

Eungoo K, Hwang HJ (2020) The consequences of data fabrication and falsification among researchers. J Res Publ Ethics 1:7-10. https:// doi.org/10.15722/jrpe.1.2.202009.7

Fanelli D (2010) Do pressures to publish increase scientists' bias? An empirical support from US States data. PLoS ONE 5:10271. https://doi.org/10.1371/journal.pone.0010271

Fanelli D, Larivière V (2016) Researchers' individual publication rate has not increased in a century. PLoS ONE 11:e0149504. https:// doi.org/10.1371/journal.pone.0149504

Fernandez-Llimos F (2016) Bradford's law, the long tail principle, and transparency in Journal Impact Factor calculations. Pharm Pract (granada) 14:842. https://doi.org/10.18549/pharmpract.2014.03. 842

Freund RJ, Mohr DL, Wilson WJ (2010) Statistical Methods, 3rd edn. Academic Press, Canada, p 795. https://doi.org/10.1016/b978-012-374970-3.00006-8

Gerding AB (2012) Ethical dilemmas in publishing. A rising tide of plagiarism? J Prosthodont 21:431-432. https://doi.org/10.1111/j. 1532-849x.2012.00904.x

Goodman S (2008) A dirty dozen: Twelve $P$-value misconceptions. Semin Hematol 45:135-140. https://doi.org/10.1053/j.seminhemat ol.2008.04.003

Grimm D (2005) Suggesting or excluding reviewers can help get your paper published. Science 309:1974. https://doi.org/10.1126/scien ce.309.5743.1974

Higgins JR, Lin FC, Evans JP (2016) Plagiarism in submitted manuscripts: incidence, characteristics and optimization of screeningcase study in a major specialty medical journal. Res Integr Peer Rev 11(1):1-8. https://doi.org/10.1186/s41073-016-0021-8
Hites RA (2021) How to convince an editor to accept your paper quickly. Sci Total Environ 798:149243. https://doi.org/10.1016/j. scitotenv.2021.149243

Hu B, Guo H, Zhou P, Shi ZL (2020) Characteristics of SARS-CoV-2 and COVID-19. Nat Rev Microbiol 193(19):141-154. https:// doi.org/10.1038/s41579-020-00459-7

Iaccarino M (2001) Science and ethics As research and technology are changing society and the way we live, scientists can no longer claim that science is neutral but must consider the ethical and social aspects of their work. EMBO Rep 2:747-750. https:// doi.org/10.1093/embo-reports/kve191

Iglewicz B (2014) Experimentwise error rate in practice. Wiley StatsRef Stat Ref Online. https://doi.org/10.1002/9781118445 112.stat05852

Ioannidis JPA (2005) Why most published research findings are false. PLOS Med 2:e124. https://doi.org/10.1371/journal.pmed. 0020124

Johnson VE (2013) Revised standards for statistical evidence. Proc Natl Acad Sci U S A 110:19313-19317. https://doi.org/10.1073/ pnas. 1313476110

Kingori P, Gerrets R (2016) Morals, morale and motivations in data fabrication: Medical research fieldworkers views and practices in two Sub-Saharan African contexts. Soc Sci Med 166:150. https://doi.org/10.1016/j.socscimed.2016.08.019

Kirk RE (2007) Effect magnitude: A different focus. J Stat Plan Inference 137:1634-1646. https://doi.org/10.1016/j.jspi.2006.09.011

Klein DF, Glick ID (2008) Conflict of interest, journal review, and publication policy. Neuropsychopharmacol 3313(33):30233026. https://doi.org/10.1038/npp.2008.109

Kotsis SV, Chung KC (2014) Manuscript rejection: how to submit a revision and tips on being a good peer reviewer. Plast Reconstr Surg 133:958-964. https://doi.org/10.1097/prs.0000000000 000002

Kumar PM, Priya NS, Musalaiah S, Nagasree M (2014) Knowing and avoiding plagiarism during scientific writing. Ann Med Health Sci Res 4:S193. https://doi.org/10.4103/2141-9248.141957

Lakens D (2013) Calculating and reporting effect sizes to facilitate cumulative science: a practical primer for t-tests and ANOVAs. Front Psychol 4:863. https://doi.org/10.3389/fpsyg.2013.00863

Lang TA (2020) An author's editor reads the "Instructions for Authors.” Eur Sci Ed 46:e55817. https://doi.org/10.3897/ese. 2020.e55817

Larivière V, Kiermer V, MacCallum CJ, McNutt M, Patterson M, Pulverer B, Swaminathan S, Taylor S, Curry S (2016) A simple proposal for the publication of journal citation distributions. Biorxiv. https://doi.org/10.1101/062109

Levesque RJR (2019) Presubmission inquiries: Problematic, counterproductive, and unnecessary. J Youth Adolesc 484(48):651-654. https://doi.org/10.1007/s10964-019-01008-z

Lew MJ (2012) Bad statistical practice in pharmacology (and other basic biomedical disciplines): you probably don't know P. Br J Pharmacol 166:1559-1567. https://doi.org/10.1111/j.1476-5381. 2012.01931.x

Lowry G, Field J, Westerhoff P, Zimmerman J, Alvarez P, Boehm A, Crittenden J, Dachs J, Diamond M, Eckelman M, Gardea-Torresdey J, Giammar D, Hofstetter T, Hornbuckle K, Jiang G, Li XD, Leusch F, Mihelcic J, Miller S, Pruden A, Raskin L, Richardson S, Scheringer M, Schlenk D, Strathmann T, Tao S, Waite TD, Wang P, Wang S (2020) Why was my paper rejected without review? Environ Sci Technol 54:11641-11644. https://doi.org/10.1021/ acs.est.0c05784

Lozano GA, Larivière V, Gingras Y (2012) The weakening relationship between the impact factor and papers' citations in the digital age. J Am Soc Inf Sci Technol 63:2140-2145. https://doi.org/10. 1002/asi.22731 
Maccaro A, Piaggio D, Pagliara S, Pecchia L (2021) The role of ethics in science: A systematic literature review from the first wave of COVID-19. Health Technol in Press. https://doi.org/10.1007/ s12553-021-00570-6

Macháček V, Srholec M (2021) Predatory publishing in Scopus: evidence on cross-country differences. Sci 1263(126):1897-1921. https://doi. org/10.1007/s11192-020-03852-4

Maestre FT (2019) Ten simple rules towards healthier research labs. PLOS Comput Biol 15:e1006914. https://doi.org/10.1371/journal.pcbi.10069 14

Masicampo EJ, Lalande DR (2012) A peculiar prevalence of P values just below .05. Q J Exp Psychol 65:2271-2279. https://doi.org/10.1080/ 17470218.2012.711335

McCabe DJ, Hayes-Pontius EM, Canepa A, Berry KS, Levine BC (2012) Measuring standardized effect size improves interpretation of biomonitoring studies and facilitates meta-analysis. Freshw Sci 31:800-812. https://doi.org/10.1899/11-080.1

McGough JJ, Faraone SV (2009) Estimating the size of treatment effects: moving beyond $P$ values. Psychiatry 6:21-29

Nakagawa S, Cuthill IC (2007) Effect size, confidence interval and statistical significance: a practical guide for biologists. Biol Rev Camb Philos Soc 82:591-605. https://doi.org/10.1111/j.1469-185x.2007.00027.x

Neill US (2008) Publish or perish, but at what cost? J Clin Invest 118:2368. https://doi.org/10.1172/jci36371

Nuzzo R (2014) Scientific method: Statistical errors. Nature 506:150-152. https://doi.org/10.1038/506150a

Pérez-Manrique A, Gomila A (2021) Emotional contagion in nonhuman animals: A review. Wiley Interdiscip Rev Cogn Sci e1560. https://doi. org/10.1002/wcs. 1560

Perreau M, Suffiotti M, Marques-Vidal P, Wiedemann A, Levy Y, Laouénan C, Ghosn J, Fenwick C, Comte D, Roger T, Regina J, Vollenweider P, Waeber G, Oddo M, Calandra T, Pantaleo G (2021) The cytokines HGF and CXCL13 predict the severity and the mortality in COVID-19 patients. Nat Commun 12:4888. https://doi.org/10.1038/ s41467-021-25191-5

Pourret O, Irawan DE, Tennant JP, Wien C, Dorch B (2020) Comments on "Factors affecting global flow of scientific knowledge in environmental sciences" by Sonne et al. (2020). Sci Total Environ 721:136454. https://doi.org/10.1016/j.scitotenv.2019.136454

Qehaja AB (2020) Avoiding publishing in predatory journals: An evaluation algorithm. J Effic Responsib Educ Sci 13:154-163. https://doi. org/10.7160/eriesj.2020.130305

Qian J, Yuan Z, Li J, Zhu H (2020) Science Citation Index (SCI) and scientific evaluation system in China. Humanit Soc Sci Commun 71(7):1-4. https://doi.org/10.1057/s41599-020-00604-w

Rawat S, Meena S (2014) Publish or perish: Where are we heading? J Res Med Sci 19:87

Resnik DB (2014) Data fabrication and falsification and empiricist philosophy of science. Sci Eng Ethics 20:423. https://doi.org/10.1007/ s11948-013-9466-Z

Rickard T, Gayley CA (eds) (1908) A guide to technical writing. Mining and Scientific Press, San Francisco

Rillig MC, Bielcik M, Chaudhary VB, Grünfeld L, Maaß S, Mansour I, Ryo M, Veresoglou SD (2020) Ten simple rules for increased lab resilience. PLOS Comput Biol 16:e1008313. https://doi.org/10.1371/ journal.pcbi.1008313

Ruff K (2015) Scientific journals and conflict of interest disclosure: what progress has been made? Environ Heal 141(14):1-8. https://doi.org/ 10.1186/s12940-015-0035-6

Sayer EJ (2018) The anatomy of an excellent review paper. Funct Ecol 32:2278-2281. https://doi.org/10.1111/1365-2435.13207

Schofferman J, Wetzel F, Bono C (2015) Ghost and guest authors: you can't always trust who you read. Pain Med 16:416-420. https://doi.org/10. 1111/pme.12579

Sedlak DL (2015) Just said no. Environ Sci Technol 49:6365-6366. https:// doi.org/10.1021/acs.est.5b02405
Senn S (2001) Two cheers for $P$-values? J Epidemiol Biostat 6:193-204. https://doi.org/10.1080/135952201753172953

Smolčić VŠ (2013) Salami publication: definitions and examples. Biochem Medica 23:237. https://doi.org/10.11613/bm.2013.030

Solís Arce JS, Warren SS, Meriggi NF, Scacco A, McMurry N, Voors M, Syunyaev G, Malik AA, Aboutajdine S, Adeojo O, Anigo D, Armand A, Asad S, Atyera M, Augsburg B, Awasthi M, Ayesiga GE, Bancalari A, Björkman Nyqvist M, Borisova E, Bosancianu CM, Cabra García MR, Cheema A, Collins E, Cuccaro F, Farooqi AZ, Fatima T, Fracchia M, Galindo Soria ML, Guariso A, Hasanain A, Jaramillo S, Kallon S, Kamwesigye A, Kharel A, Kreps S, Levine M, Littman R, Malik M, Manirabaruta G, Mfura JLH, Momoh F, Mucauque A, Mussa I, Nsabimana JA, Obara I, Otálora MJ, Ouédraogo BW, Pare TB, Platas MR, Polanco L, Qureshi JA, Raheem M, Ramakrishna V, Rendrá I, Shah T, Shaked SE, Shapiro JN, Svensson J, Tariq A, Tchibozo AM, Tiwana HA, Trivedi B, Vernot C, Vicente PC, Weissinger LB, Zafar B, Zhang B, Karlan D, Callen M, Teachout M, Humphreys M, Mobarak AM, Omer SB (2021) COVID-19 vaccine acceptance and hesitancy in lowand middle-income countries. Nat Med 27:1385-1394. https://doi.org/ 10.1038/s41591-021-01454-y

Sonne C, Dietz R, Alstrup AKO (2020) Factors affecting global flow of scientific knowledge in environmental sciences. Sci Total Environ 701:135012. https://doi.org/10.1016/j.scitotenv.2019.135012

Stehr N (2009) Useful Scientific Knowledge: What Is Relevant Science for Society? on JSTOR. J Appl Soc Sci 3:18-29

Sullivan GM, Feinn R (2012) Using effect size-or why the $P$ value is not enough. J Grad Med Educ 4:279-282. https://doi.org/10.4300/ jgme-d-12-00156.1

Telenti A, Arvin A, Corey L, Corti D, Diamond MS, García-Sastre A, Garry RF, Holmes EC, Pang P, Virgin HW (2021) After the pandemic: perspectives on the future trajectory of COVID-19. Nature 596:495-504. https://doi.org/10.1038/s41586-021-03792-w

Thorlindsson T, Vilhjalmsson R (2016) Introduction to the special issue: Science, knowledge and society. Acta Sociol 46:99-105

Tomczak M, Tomczak E (2014) The need to report effect size estimates revisited. An overview of some recommended measures of effect size. TRENDS Sport Sci 1:19-25

Van Wesel M (2016) Evaluation by citation: Trends in publication behavior, evaluation criteria, and the strive for high impact publications. Sci Eng Ethics 22:225. https://doi.org/10.1007/s11948-015-9638-0

Van Noorden R, Singh Chawla D (2019) Hundreds of extreme self-citing scientists revealed in new database. Nature 572:578-579. https://doi. org/10.1038/d41586-019-02479-7

Veresoglou SD (2015) P hacking in biology: An open secret. Proc Natl Acad Sci U S A 112:E5112. https://doi.org/10.1073/pnas.1512689112

Verma IM (2015) Impact, not impact factor. Proc Natl Acad Sci U S A 112:7875. https://doi.org/10.1073/pnas.1509912112

von Wehrden H, Schultner J, Abson DJ (2015) A call for statistical editors in ecology. Trends Ecol Evol 30:293-294. https://doi.org/10.1016/j. tree.2015.03.013

Vuong QH (2019) Breaking barriers in publishing demands a proactive attitude. Nat Hum Behav 310(3):1034-1034. https://doi.org/10. 1038/s41562-019-0667-6

Xafis V, Schaefer GO, Labude MK, Zhu Y, Hsu LY (2020) The perfect moral storm: Diverse ethical considerations in the COVID-19 pandemic. Asian Bioeth Rev 12:65-83. https://doi.org/10.1007/ s41649-020-00125-3

Yiaslas T (2019) The pursuit of arete in medicine and health care. Int J Dis Reversal Prev 1:4-4. https://doi.org/10.22230/ijdrp.2019v1n2a105

Zhu JW (2020) Evaluation of scientific and technological research in China's colleges: A review of policy reforms, 2000-2020. ECNU Rev Educat 3:556-561. https://doi.org/10.1177/2096531120938383

Publisher's Note Springer Nature remains neutral with regard to jurisdictional claims in published maps and institutional affiliations. 